\title{
Percepción de la satisfacción de la función familiar que tienen los pacientes de diálisis peritoneal
}

\author{
Carmen Puigvert Vilalta
}

Unidad de díalisis. Hospital Universitario Dr. Josep Trueta. Girona

\section{Introducción:}

La familia es una unidad biopsicosocial que tiene un comportamiento como tal frente a la salud y a la atención sanitaria, de manera que, mediante la transmisión de creencias y valores de padres a hijos, todo el proceso que acontece desde que reconoce una enfermedad hasta que se cura o desaparece, en caso de las enfermedades crónicas se adapta, está influido por las decisiones que se adoptan en el seno del grupo familiar (2). Se define a la familia sana como aquella que desempeña adecuadamente sus funciones, y es por tanto normofuncional. El Apgar-familar es un instrumento útil para conocer si la familia puede considerarse un recurso para los individuos del grupo, o por el contrario influirá empeorando la situación. El Apgar-familiar es una técnica rápida para explorar la función familiar, que fue desarrollada por Smilkstein en 1978 (8) y se encuentra validada en nuestro país por Bellon y cols (1996). "Validez y fiabilidad del cuestionario de función familiar Apgar-familiar" (9). Presenta una Fiabilidad: test-retest es superior a 0.75 y tiene una buena consistencia interna: (alfa de Cronbach 0.84). Para establecer los parámetros por los cuales la salud funcional de la familia pudiera ser medida, se escogieron cinco componentes básicos: Adaptabilidad, Participación, Crecimiento, Afecto y Resolución. Estos cinco componentes se evalúan a través de un cuestionario que consta de cinco ítems independientes para valorar la percepción de la persona sobre la función familiar. Objetivo: Conocer las tipologías de familia y el grado de satisfacción respecto al funcionamiento familiar que tienen los pacientes con insuficiencia renal crónica terminal en tratamiento de diálisis peritoneal.

\section{Metodología:}

Esta investigación es de tipo cuantitativo, de diseño descriptivo y de corte transversal. La población del estudio son todos los pacientes, de la región sanitaria de Girona, que han escogido la diálisis peritoneal. EI período del estudio es de enero de 2012 a diciembre de 2012. Criterios de inclusión son la población adulta, que han entrado en programa de crónicos y que realizan diálisis peritoneal como tratamiento substitutivo de la función renal. Criterios de exclusión son los pacientes inmigrantes con dificultad en el idioma y sin soporte para la interpretación correcta del cuestionario y los que no aceptan entrar en el estudio. Las encuestas son anónimas, autoadministradas y se entregan un día de visita, para la recogida se coloca una caja para ser depositadas. Variables sociodemogràfiques: Edad, Sexo y Situación de convivencia familiar: vive solo, en familia, en compañía. El Apgar-familar se valora con una escala tipo likert que se califica: casi nunca $=0$; a veces $=1$; y casi siempre $=2$ Los puntos de corte son: normofuncional de 7-10, disfuncional leve de 3-6 y disfuncional grave de 0-2. Previo al estudio se pide el consentimiento informado por escrito, quedándose una copia el participante y otra el investigador.

\section{Resultado:}

$\mathrm{n}=60,40$ hombres y 20 mujeres. Edad media 57,7a. Situación convivencia: $11,7 \%$ vive solo, $75 \%$ vive en familia y $13,3 \%$ vive en compañía. Apgar familiar: Normofuncionales $85 \%$, disfuncionales leves $13,3 \%$ y disfuncional grave $1,7 \%$. 


\section{Referencias Bibliográficas}

1. Ríos Arias C, Velásquez Serna Y. Incluir a la familia en el cuidado: una meta de la enfermería. Educare21 2004; 14. [consultado 28 enero 2013]. Disponible en: http://enfermeria21.com/educare/educare.

2. Fuentes Biggi J. El sistema, la comunicación y la familia. En: Suárez T; Rogero GF. Paradigma sistémico y terapia de familia. Madrid: Asociación Española de Nueropsiquiatría, 1983.

3. Lima Rodríguez JS, Lima Serrano M. Valoración enfermera de la familia. Guía básica. [consultado 28 enero 2013]. Disponible en http://rodas.us.es/ items/e15d054f-757a-3d84-0345.

4. González I. Reflexiones acerca de la Salud Familiar. Revista Cubana de Medicina General Integral. 2000; 16: 508-512. [consultado 29 enero 2013]. Disponible en: http://scielo.sld.cu/scielo.

5. De la Revilla L. Disfunción familiar. Aten Primaria 1992; 10: 582-583.

6. De la Revilla L. Por qué es necesaria la atención familiar. En: De la Revilla L, eds. Conceptos e instrumentos de la atención familiar. Barcelona: Ed Doyma, 1994; 1-6.

7. Horwitz N, Florenzano R, Ringeling I. Familia y salud familiar. Un enfoque para la atención prima- ria. Boletín de la Oficina Sanitaria Panamericana 1985; 98: 144-154.

8. Gómez Clavelina FJ, Ponce Rosas ER. Una nueva propuesta para la interpretación de Family APGAR (versión en español) Aten Fam 2010; 17(4): 102-106.

9. Bellón SJA, Delgado SA, Luna del CJD, Lardelli CP. Validez y fiabilidad del cuestionario de función familiar Apgar-familiar. Atención Primaria 1996; 18(6):289-295.

10. Lima Rodríguez JS, Lima Serrano M, Jiménez Picón N y Domínguez Sánchez I. Consistencia interna y validación de un cuestionario para medir la autopercepción del estado de salud familiar. [consultado 28 enero 2013]. Disponible en: http://scielo. isciii.es/scielo.

11. Vargas Migdalia Cerino G. Funcionalidad familiar en los pacientes del programa de diálisis peritoneal a través del método apgar familiar. [Consultado 28 enero 2013]. Disponible en: http://www.portalesmedicos.com.

12. Rodríguez Vázquez BS, Diálisis peritoenal continua ambulatoria: principales complicaciones y factores asociados. Tesis de post grado para obtener el título en la especialidad de medicina familiar. IMSS Orizaba, Veracruz México 2011 . [consultado 30 enero 2013]. Disponible en: cdigital. uv.mx/bitstream/. 